Article

\title{
The Association of Tanacetum parthenium and Salix alba Extracts Reduces Cortex Serotonin Turnover, in an Ex Vivo Experimental Model of Migraine
}

\author{
Simonetta Cristina Di Simone ${ }^{1,2,+}$, Alessandra Acquaviva ${ }^{1,3,+} \mathbb{D}$, Maria Loreta Libero ${ }^{1} \mathbb{D}$, Annalisa Chiavaroli ${ }^{1}$, \\ Lucia Recinella ${ }^{1}$, Sheila Leone ${ }^{1}$, Luigi Brunetti ${ }^{1}$, Matteo Politi ${ }^{1}$ (D), Claudia Giannone ${ }^{1}$, Claudia Campana $^{1}$, \\ Giustino Orlando ${ }^{1}$, Gokhan Zengin ${ }^{4}\left(\mathbb{D}\right.$, Massimo Tacchini ${ }^{5, *} \mathbb{D}$, Luigi Menghini ${ }^{1, *(D)}$ and Claudio Ferrante ${ }^{1}$ (D)
}

Citation: Di Simone, S.C.; Acquaviva,

A.; Libero, M.L.; Chiavaroli, A.;

Recinella, L.; Leone, S.; Brunetti, L.;

Politi, M.; Giannone, C.; Campana, C.; et al. The Association of Tanacetum parthenium and Salix alba Extracts Reduces Cortex Serotonin Turnover, in an Ex Vivo Experimental Model of Migraine. Processes 2022, 10, 280. https://doi.org/10.3390/pr10020280

Academic Editor: Maria Angela A. Meireles

Received: 28 December 2021

Accepted: 27 January 2022

Published: 30 January 2022

Publisher's Note: MDPI stays neutral with regard to jurisdictional claims in published maps and institutional affiliations.

Copyright: (c) 2022 by the authors Licensee MDPI, Basel, Switzerland. This article is an open access article distributed under the terms and conditions of the Creative Commons Attribution (CC BY) license (https:// creativecommons.org/licenses/by/ $4.0 /)$.
1 Department of Pharmacy, Botanic Garden "Giardino dei Semplici", "Gabriele d'Annunzio" University, Via dei Vestini 31, 66100 Chieti, Italy; simonetta.disimone@unich.it (S.C.D.S.); alessandra.acquaviva@unich.it (A.A.); maria.libero@unich.it (M.L.L.); annalisa.chiavaroli@unich.it (A.C.); lucia.recinella@unich.it (L.R.); sheila.leone@unich.it (S.L.); luigi.brunetti@unich.it (L.B.); matteo.politi@unich.it (M.P.); claudia.giannone@studenti.unich.it (C.G.); claudia.campana@studenti.unich.it (C.C.); giustino.orlando@unich.it (G.O.); claudio.ferrante@unich.it (C.F.)

2 Cristalfarma S.R.L., Via San Giuseppe Cottolengo, 20143 Milan, Italy

3 Veridia Italia S.R.L., Via Raiale 285, 65100 Pescara, Italy

4 Biochemistry and Physiology Research Laboratory, Department of Biology, Faculty of Science, Selcuk University, Konya 42130, Turkey; gokhanzengin@selcuk.edu.tr

5 Department of Life Sciences and Biotechnology (SVeB), UR7 Terra\&Acqua Tech, University of Ferrara, 44121 Ferrara, Italy

* Correspondence: massimo.tacchini@unife.it (M.T.); luigi.menghini@unich.it (L.M.)

$\dagger$ These authors contributed equally to this work.

\begin{abstract}
The mixture of water extracts from Tanacetum parthenium and Salix alba was studied in an ex vivo assessment of neurotoxicity constituted by isolated mouse cortex specimens challenged with $\mathrm{K}^{+} 60 \mathrm{mM}$ Krebs-Ringer buffer (neurotoxicity stimulus). The effects of the mixture on lactate dehydrogenase $(\mathrm{LDH})$, nitrite and serotonin levels were investigated. The phytochemical profile of the mixture was also evaluated. A docking approach was conducted to predict, albeit partially, the putative mechanism underlying the observed effects. The extracts displayed a good profile of polyphenolic compounds (22 chromatographic peaks detected), with caftaric acid and epicatechin being the prominent phenols. In isolated cortex, the association of T. parthenium and S. alba extracts was effective in reducing the $\mathrm{K}^{+} 60 \mathrm{mM}$-induced levels of $\mathrm{LDH}$ and nitrites, whereas the neurotoxicity stimulus-induced serotonin depletion was prevented by the treatment. Regarding the inhibition of serotonin catabolism, epicatechin $(44.65 \mu \mathrm{g} / \mathrm{mg})$ and caftaric acid $(10.51 \mu \mathrm{g} / \mathrm{mg})$ were putatively the main compounds involved in the inhibition of monoamineoxidase- $\mathrm{A}$, which is known to play a master role in serotonin turnover. Collectively, the results of the present study point to the efficacy of the present extract mixture as an innovative pharmacological tool to prevent the onset of migraine.
\end{abstract}

Keywords: migraine; serotonin; cortical spreading depression; oxidative stress; Tanacetum parthenium; Salix alba; phenolic compounds

\section{Introduction}

Migraine is one of the most widespread neurovascular disorders, with an incidence which increases during aging, especially in women [1]. Serotonin (5-HT) has long been involved in migraine etiopathogenesis, with clinical data pointing to tight relationships between neurotransmitter activity and migraine attacks [2]. In this context, the activation of 5-HT1B and 5-HT1D receptors could lead to the control of migraine attacks [3]; by contrast, the blockade of the 5-HT2A and 5-HT2C receptors was found effective in the prevention therapy [4]. The involvement of the trigemino-vascular system and neuroinflammation has 
also been demonstrated in the pathophysiology of migraine [5,6], although the site of origin of migraine is still unsettled. However, cortical spreading depression (CSD), a supraphysiological neurotoxicity stimulus, has been related to the migraine onset. In particular, CSD would represent a possible link between 5-HT depletion and trigeminal nociception [7]. Currently, the pharmacotherapy options for migraine include aborting attack treatments, namely analgesics, nonsteroidal anti-inflammatory drugs, and triptans [8], and preventive medications, including anti-epileptics, anti-depressants and anti-hypertensives [9]. More recently, monoclonal antibody therapy has been demonstrated to be effective and tolerated by migraineurs [10]. Nevertheless, despite there being different and efficacious pharmacological treatments for the management of migraine, the frequent occurrence of side effects is an impulse to search for innovative options with a minor impact, in terms of side effects [11,12]. Specifically, a new perspective is arising from the anti-migraine use of nutraceuticals and botanicals [12]. Among botanicals, a promising approach is represented by the use of extracts from T. parthenium and Salix alba, which are known to possess anti-inflammatory effects $[13,14]$. T. parthenium has been used with success for preventing migraine attacks in both adult and child patients $[15,16]$, whereas $S$. alba improved 5-HT level in rat hippocampus after in vivo administration [17]. Both were found effective, as single treatments, to prevent 5-HT turnover, in a preclinical experimental model of CSD $[18,19]$. The scientific literature has suggested their pharmacological association for migraine prophylaxis [20]. The co-administration of magnesium and coenzyme Q10 would further improve the anti-migraine efficacy of these botanicals [15].

In this context, the aim of the present study was to investigate the potential use of the extract mixture of T. parthenium and S. alba water extracts in an ex vivo model of CSD constituted by isolated mouse cortex specimens exposed to an supraphysiological depolarizing stimulus $\left(\mathrm{K}^{+} 60 \mathrm{mM}\right)$. The abovementioned ingredients have been reconstituted in water, and their effects on 5-HT turnover and markers of nitrosative stress and tissue damage, namely nitrites and lactate dehydrogenase, were assayed as well $[17,18,21]$. The tolerability of the formula was also evaluated through validated toxicological models, namely the Artemia salina and Daphnia magna toxicity tests [22]. Finally, phytochemical and in silico analyses were also conducted in order to shed light the mechanism of action underlying the observed bio-pharmacological effects.

\section{Results and Discussion}

\subsection{Phytochemical Analysis}

The extract mixture was formerly investigated via qualitative MS analysis (scan mode $100-1200 \mathrm{~m} / \mathrm{z}$ ), for confirming the presence of parthenolide and salicin, which are reference compounds in T. parthenium and S. alba, respectively. The m/z 249.3 and 271.1 were monitored in positive scan mode to identify the parthenolide, and the MS spectrum confirmed the presence of parthenolide, in the mixture (Figure 1). The $\mathrm{m} / \mathrm{z}$ ratio 285.1 was scanned in negative scan mode for the identification of salicin, whose MS spectrum is shown (Figure 2). The abovementioned $\mathrm{m} / \mathrm{z}$ ratios were selected according to the MS spectra reported in MassBankEurope databases. Regarding parthenolide, the selection of the $\mathrm{m} / \mathrm{z} 249.3$ agrees with the study by Zhao et al. (2016) [23]. In the case of salicin, the $\mathrm{m} / \mathrm{z}$ ratio was also considered on the basis of the study by Kammerer and colleagues (2005) [24]. These authors observed that ionization-induced salicin derivatives tended partially to decompose to $\mathrm{m} / \mathrm{z}$ 123 , forming its aglycone form, namely saligenin.

The phytochemical composition was also studied through HPLC-DAD-MS, with the aim of elucidating the quali-quantitative profile in phenolic compounds (Table 1), deeply involved in the anti-inflammatory and anti-oxidant effects of herbal extracts, especially from plant materials extracted with polar solvents [25]. Specifically, the quantitative chromatographic analysis, whose experimental conditions are depicted in Table 1, indicated epicatechin $(277.89 \mu \mathrm{g} / \mathrm{mL})$ and caftaric acid $(123.93 \mu \mathrm{g} / \mathrm{mL})$ as the main phenolics (Figure 3). These compounds were also prominent in other plant materials with intriguing anti-oxidant properties, namely grape and pomace [26-28]. However, if catechins and 
caftaric acid were identified in plants belonging to the Tanaceutm taxa [29-31], Salix species were described to synthesize catechins and other polyphenolic compounds, including apigenin, luteolin, naringenin and quercetin [32]. A qualitative ${ }^{1} \mathrm{H}-\mathrm{NMR}$ analysis was also conducted in the water suppression signal mode [33], and confirmed the presence of phenolics, but also sugars (Figure 4). The presence of sugars is indicated by the chemical shift values, in the range 3-4 ppm. Considering the elevated level $(15 \% w / w)$ of salicin in the $S$. alba extract, we cannot exclude that the signals in this chemical shift range could be related, albeit in part, to this glucoside, as also suggested by the ${ }^{1} \mathrm{H}-\mathrm{NMR}$ spectrum reported in the PubChem database. However, the content of phenolics is witnessed by the signals at chemical shift values in the range 7-8 [34-36]. Nevertheless, future studies with independent analytical methods, such as ${ }^{1} \mathrm{H}-\mathrm{NMR}$ over $400 \mathrm{MHz}$ and LC-HR-MS/MS, will improve our knowledge about the phenolic composition of the extract mixture [37]. The phytochemical profile is also consistent with intrinsic antiradical and neuroprotective properties of T. parthenium and S. alba extracts [18,38-40]. Moreover, considering the ability of catechins to cross the blood brain barrier [41], it is rational to evaluate the efficacy of herbal extracts based on these plants in reversing the burden of oxidative stress and neuroinflammation which occurs in neurological diseases, such as migraine. Therefore, after the evaluation of the biocompatibility limits with ecotoxicological models, the extract mixture was administered to isolated mouse cortex specimens exposed to a neurotoxicity stimulus $\left(\mathrm{K}^{+} 60 \mathrm{mM}\right)$, and selected biomarkers, including serotonin, were assayed for evaluating neuroprotective and antimigraine effects.
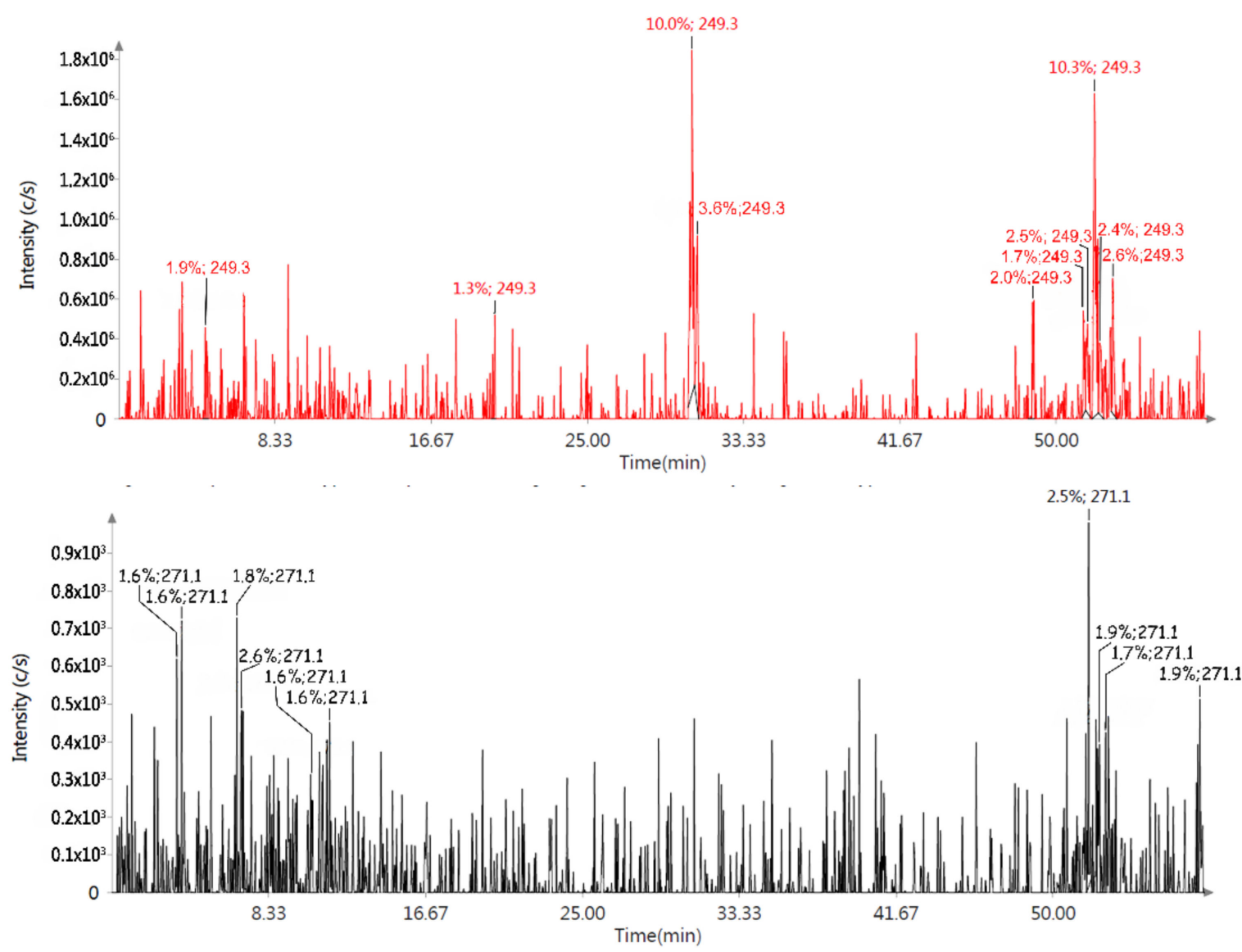

Figure 1. Qualitative mass spectrometry (MS) analysis conducted on the extract mixture. The MS analysis was conducted in positive ion mode (m/z scan mode: 100-1200), and the $\mathrm{m} / \mathrm{z}$ ratios of 249.3 and 271.1 were monitored to identify the parthenolide. The present $\mathrm{m} / \mathrm{z}$ ratios were selected on MassBankEurope database. 


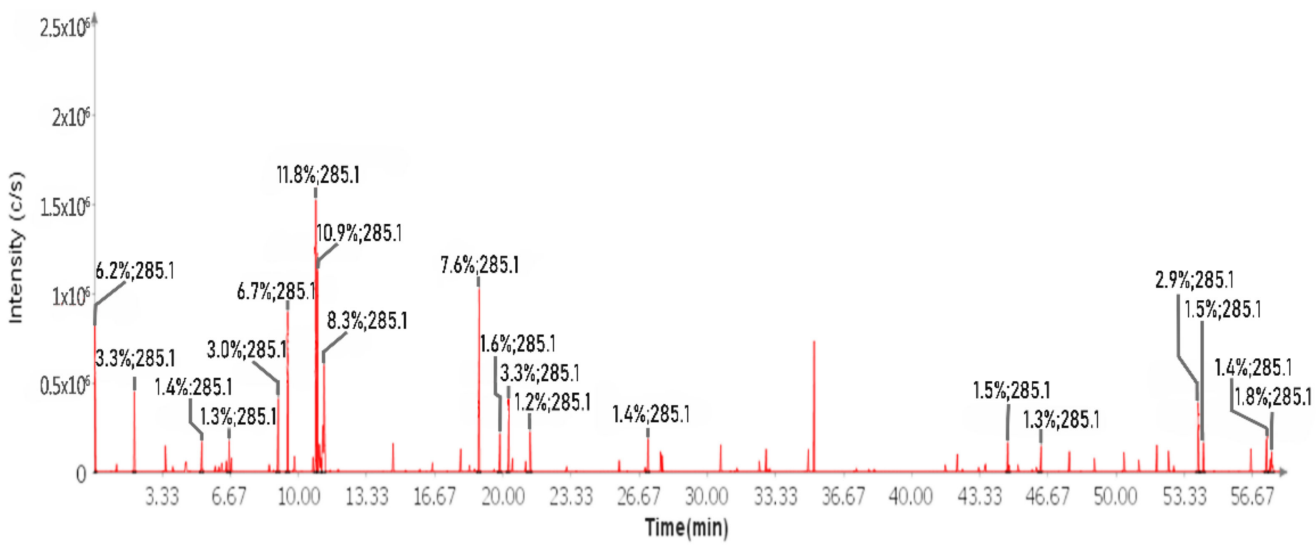

Figure 2. Qualitative mass spectrometry (MS) analysis conducted on the extract mixture. The MS analysis was conducted in negative ion mode (m/z scan mode: 100-1200), and the m/z ratio of 285.1 was monitored to identify the salicin. The present $\mathrm{m} / \mathrm{z}$ ratio was selected on MassBankEurope database.

Table 1. Wavelengths of quantification, mass to charge $(\mathrm{m} / \mathrm{z})$ ratios and retention times related to the investigated phenolic compounds.

\begin{tabular}{cccccc}
\hline Standard & $\mathbf{m} / \mathbf{z}$ & $\begin{array}{c}\text { Wavelengths } \\
(\mathbf{n m})\end{array}$ & $\begin{array}{c}\text { Retention } \\
\text { Time }(\mathbf{m i n})\end{array}$ & $\begin{array}{c}\text { Quantity } \\
(\boldsymbol{\mu g} / \mathbf{m L})\end{array}$ \\
\hline 1 & Gallic acid & 169.1 & 254 & 7.730 & 3.26382 \\
2 & Caftaric acid & 311.2 & 254 & 9.483 & 123.930 \\
3 & Catechin & 289.3 & 254 & 9.773 & 18.4077 \\
4 & Chlorogenic acid & 353.31 & 254 & 10.340 & 28.0985 \\
5 & Epicatechin & 289.3 & 254 & 11.820 & 277.890 \\
6 & Caffeic acid & 179.16 & 254 & 12.987 & 0.897624 \\
7 & Syringic acid & 197.17 & 254 & 14.183 & 1.65113 \\
8 & Syringaldheyde & 181.17 & 254 & 17.993 & 25.5515 \\
9 & Chicoric acid & 473.37 & 254 & 19.927 & 4.56034 \\
10 & Coumaric acid & 163.04 & 254 & 20.743 & 2.44522 \\
11 & Ferulic acid & 193.1 & 254 & 24.440 & 0.538303 \\
12 & Benzoic acid & 121.12 & 254 & 29.360 & 15.6476 \\
13 & Quercetin & 301.24 & 254 & 29.770 & 0.155763 \\
14 & Cinnamic acid & 147.16 & 254 & 31.460 & 4.46950 \\
15 & Hesperitin & 609.19 & 254 & 0.101043 \\
\hline
\end{tabular}

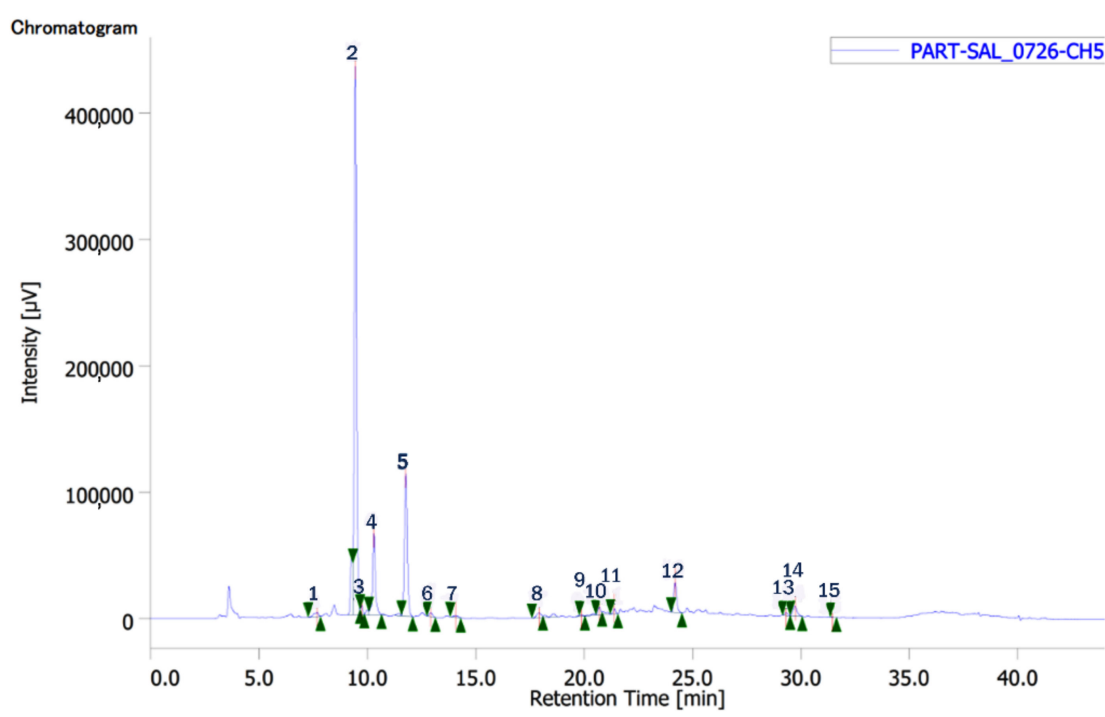

Figure 3. Chromatographic analysis of phenolic compounds, in the formula $(20 \mathrm{mg} / \mathrm{mL})$. Caftaric acid (peak \#2; Rt: 9.483 min; Conc.: $123.93 \mu \mathrm{g} / \mathrm{mL}$ ) and epicatechin (peak \#5; Rt: 11.820 min; Conc.: $277.89 \mu \mathrm{g} / \mathrm{mL}$ ) were the prominent compounds. 


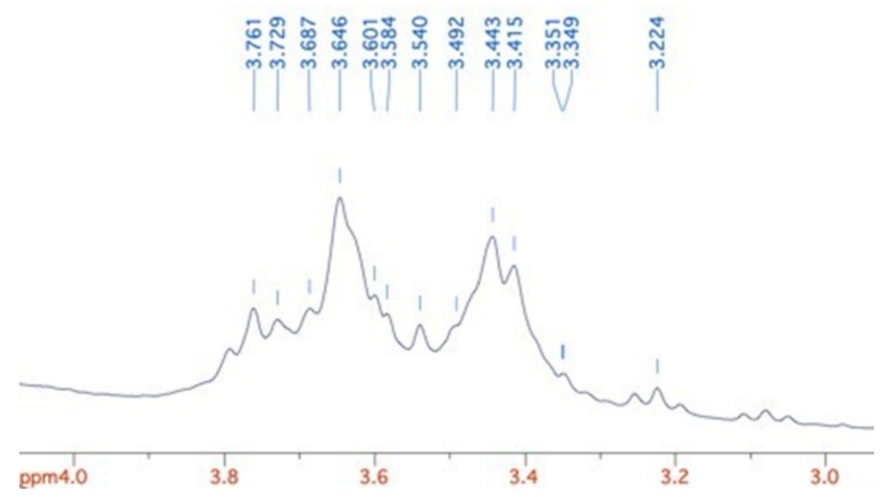

(A)

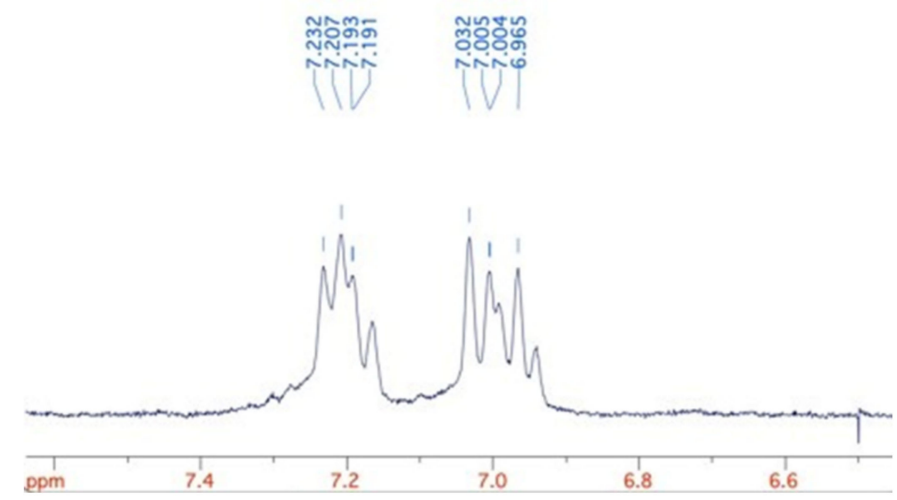

(B)

Figure 4. Qualitative composition of the formula shown by ${ }^{1} \mathrm{H}-\mathrm{NMR}$ analysis with suppression of water signal. (A) In the chemical shift range 3-4, the presence of sugar fraction is shown. In the chemical shift range 7-8 (B), the signals of phenolic compounds are shown.

\subsection{Toxicological and Pharmacological Studies}

The toxicological properties of the mixture T. parthenium/S. alba $(1: 2, w / w)$ were initially assayed through the Artemia salina (brine shrimp) lethality assay, to define the biocompatibility of the product in the concentration range $0.1-20 \mathrm{mg} / \mathrm{mL}$ [22]. This test is considered, albeit partially, as a reliable alternative model for predicting cytotoxicity, in eukaryotic cells [42]. Specifically, the mixture yielded a $\mathrm{LC}_{50}>2 \mathrm{mg} / \mathrm{mL}$ (Figure 5), which mirrored the toxicity of T. parthenium and S. alba, in the same experimental model [17]. Considering the results of the brine shrimp assay, the mixture was tested at the concentration of $2 \mathrm{mg} / \mathrm{mL}$ in the Daphnia magna toxicity test, for evaluating eventual cardiotoxicity effects, in respect to ethanol $10 \%$ solution, as representing the reference cardiotoxicity stimulus. At the concentration of $2 \mathrm{mg} / \mathrm{mL}$, the mixture was able to prevent the ethanol-induced reduction of heart rate, in Daphnia magna (Figure 6); thus scaling back its toxicity impact in eukaryotic organisms. This is also consistent with the abovementioned phytochemical profile; the Toxicity Estimation Software Tool (T.E.S.T.) predicted $\mathrm{LC}_{50}$ values $>3 \mathrm{mg} / \mathrm{mL}$ for salicin, catechins and caftaric acid, in this experimental model [22]. Nevertheless, a concentration of the mixture at least ten-fold lower $(200 \mu \mathrm{g} / \mathrm{mL})$ was selected for the subsequent evaluation on cortex tissue. This choice is motivated by the high susceptibility of neurons to oxidative and nitrosative stress [42], and also by the intrinsic capability of phenolics to induce mild oxidative stress [43].

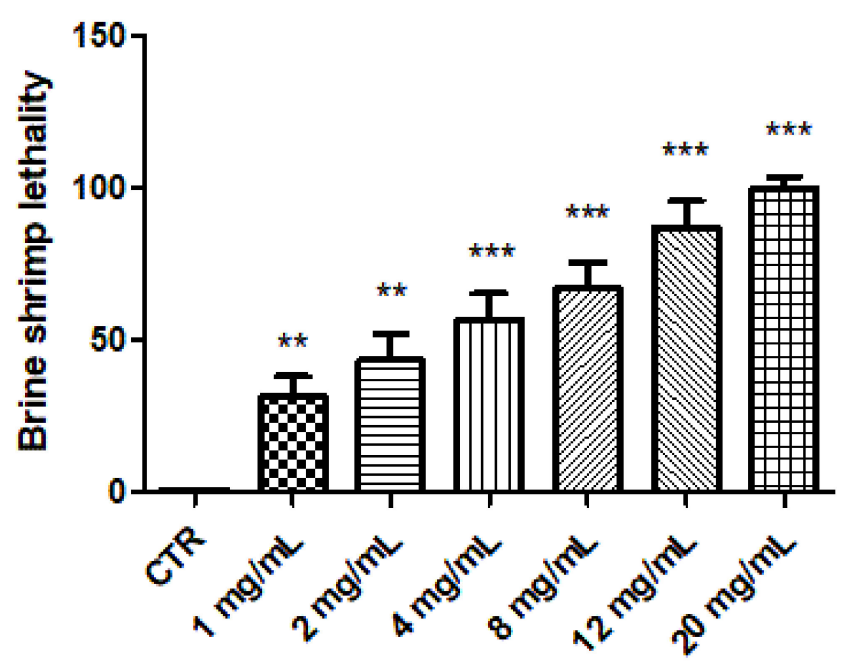

Figure 5. Effects induced by the mixture $(\mathrm{mg} / \mathrm{mL})$ on the survival of Artemia salina (brine shrimp lethality assay). ANOVA, $p<0.0001$; $^{* * *} p<0.001{ }^{* *} p<0.01$ vs. CTR. 


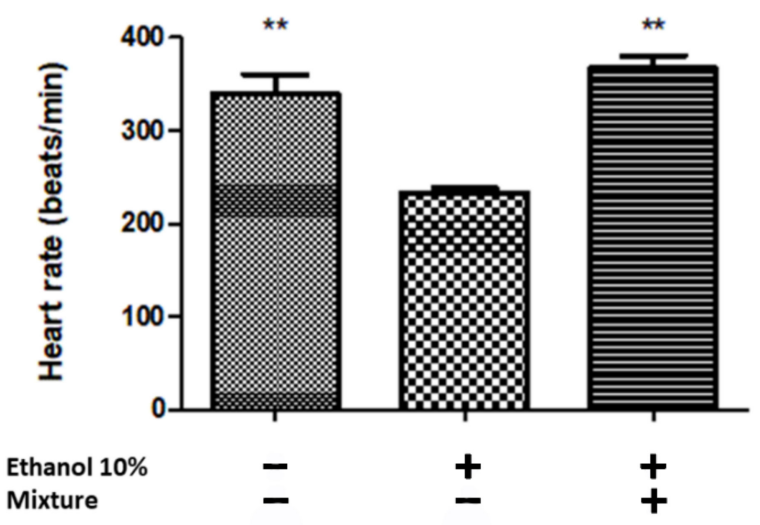

Figure 6. Effects induced by the mixture $(2 \mathrm{mg} / \mathrm{mL})$ on heart rate in the Daphnia magna toxicity model. ANOVA, $p<0.001 ;{ }^{* *} p<0.01$ vs. EtOH $10 \%$, this last representing the positive control toxicity group.

Specifically, the mixture $(200 \mu \mathrm{g} / \mathrm{mL})$ was tested in isolated mouse cortex specimens exposed to different concentrations $(3,15,60 \mathrm{mM})$ of $\mathrm{K}^{+}$, in the Krebs-Ringer buffer. If $\mathrm{K}^{+}$ 3 and $15 \mathrm{mM}$ are classical basal and depolarizing conditions in neuronal endings, respectively [44], $\mathrm{K}^{+} 60 \mathrm{mM}$ represents a supraphysiological depolarizing stimulus, also called CSD and able to induce a massive calcium-independent release, with concomitant increase of neurotransmitter degradation [7]. The CSD is common to different neuroinflammatory conditions, including migraine, and it is characterized by increased oxidative stress and serotonin degradation in the cortex [21]. In the present study, the mixture was found effective in inducing protective effects in mouse cortex. Indeed, the treatment determined a significant reduction of lactate dehydrogenase (LDH) level (Figure 7), a well-known marker of cytotoxicity [45], at all pharmacological conditions; thus suggesting not only the capability to prevent the tissue damage induced by $\mathrm{K}^{+} 60 \mathrm{mM}$, but also an intrinsic biocompatibility when cortex was exposed to physiological $\mathrm{K}^{+} 3$ and $15 \mathrm{mM}$. This biocompatibility is consistent with the abovementioned ecotoxicological predictions, and also mirrored by the inhibition of nitrite level (Figure 8), a reliable index of nitric oxide production and nitrosative stress [46], at all considered depolarizing conditions. This indicated not only the capability to contrast the burden of nitrosative stress induced by $\mathrm{K}^{+} 60 \mathrm{mM}$, but also protective effects occurring at physiological conditions. Finally, the mixture was also effective in blunting the $\mathrm{K}^{+} 60 \mathrm{mM}$-induced turnover of 5-HT, measured as 5HIIA/5-HT ratio (Figure 9), which is a reliable marker of MAO-A activity [47]. In this case, the mixture was effective at all depolarizing conditions to which the cortex was exposed. These findings further support the use of food supplements based on T. parthenium and S. alba for contrasting and/or preventing migraine attacks. The blunting effects on nitrite level and serotonin degradation could be due to more than one reason. On the one hand, we have to consider the intrinsic antiradical properties of both T. parthenium and S. alba extracts [17], present in this mixture. On the other hand, we have to highlight how the antiradical properties of herbal extracts are strictly related to enzyme inhibition effects, especially in the case of phenolic compounds [48]. Additionally, catechin has been suggested to act as a MAO-A inhibitor [49], whereas there is still a gap in the scientific literature about the effect of caftaric acid on this enzyme. Therefore, a docking approach was conducted with the aim of exploring putative interactions of caftaric acid with MAO-A, which could be predictive of enzyme inhibition effects [50]. The results of the virtual screening indicated the capability of caftaric acid to interact with the pocket/binding site of the enzyme through non-covalent interactions, including hydrogen, electrostatic and hydrophobic bonds (Figure 10). Specifically, it predicted the ability of caftaric acid to form hydrogen bonds with Ala-111, Phe-112, Thr-204, Pro-114, His-488, and to interact via electrostatic bond with Glu-492. A hydrophobic interaction was predicted with Phe-112, as well. Furthermore, the present and literature data showed micromolar affinities of caftaric acid and epicatechin, respectively, towards the MAO-A enzyme; thus suggesting the occurrence of enzyme inhibition effects by the 
mixture and underlying the observed reduction of 5-HT turnover. Considering the 5-HT depletion occurring in migraine, the inhibition of 5-HT turnover induced by the mixture could be of relevance for the prevention of attacks, in migraineurs.

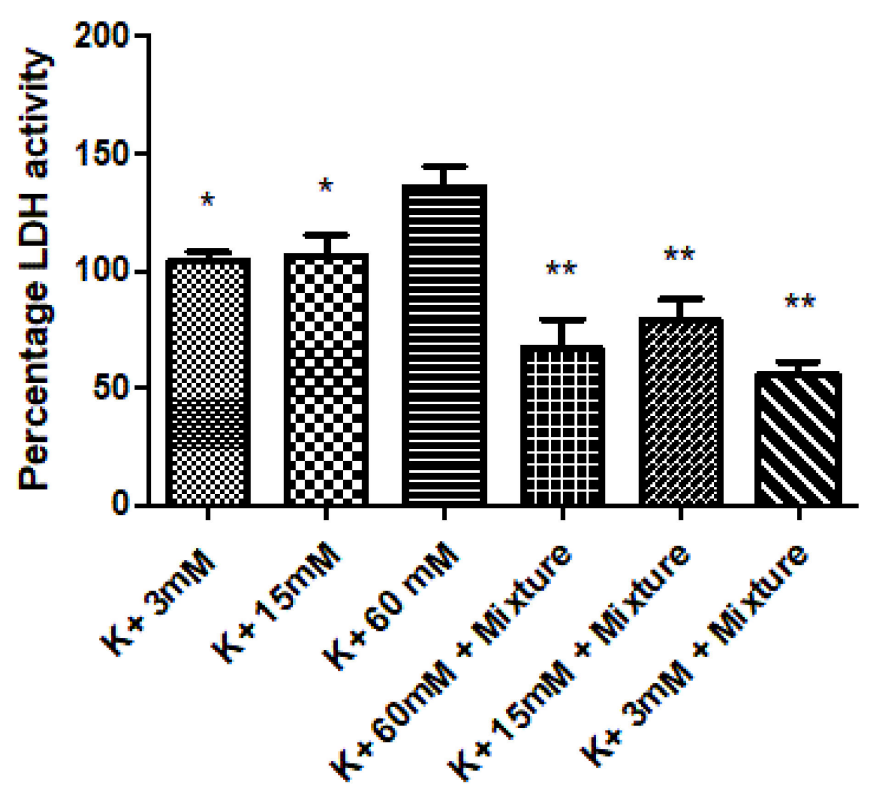

Figure 7. Inhibitory effect induced by the mixture $(200 \mu \mathrm{g} / \mathrm{mL})$ on lactate dehydrogenase (LDH) level, in isolated mouse cortex specimens. ANOVA, $p<0.001 ;{ }^{* *} p<0.01{ }^{*} p<0.05 \mathrm{vs}$. $\mathrm{K}^{+} 60 \mathrm{mM}$.

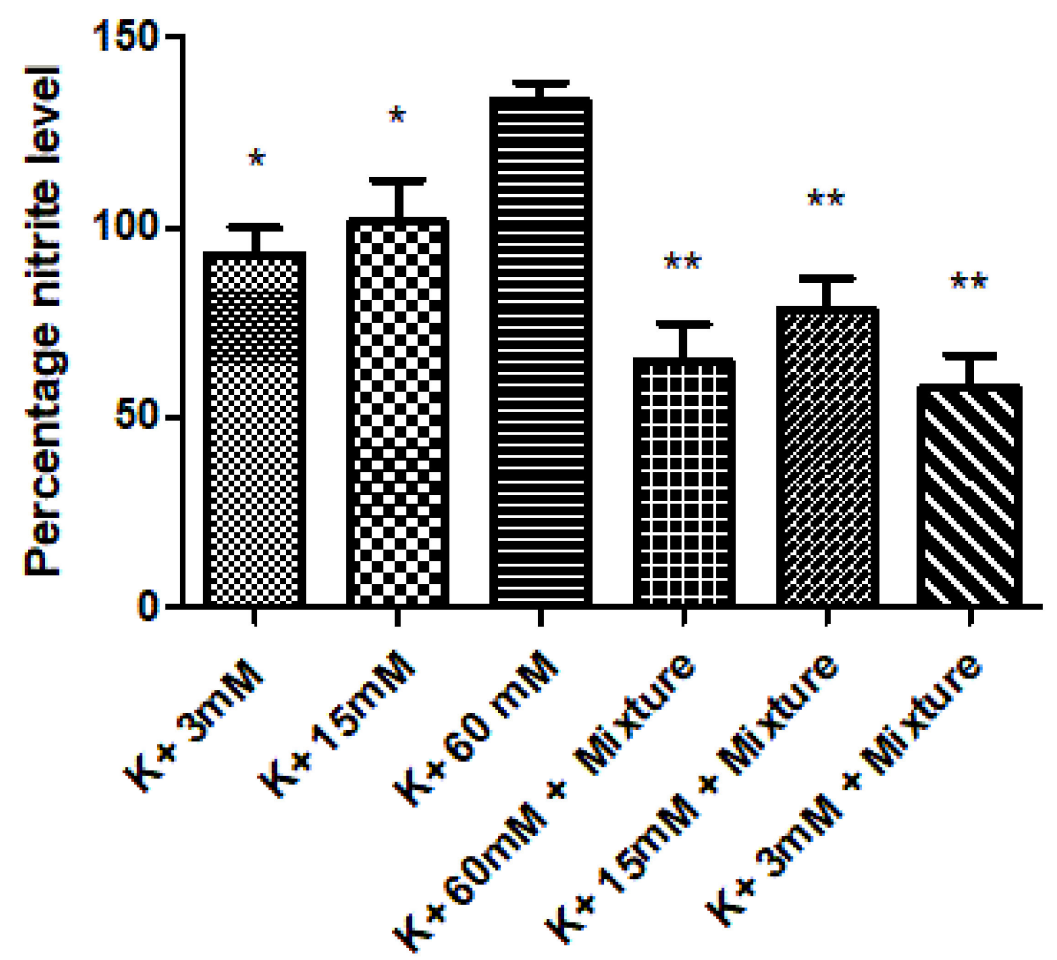

Figure 8. Inhibitory effect induced by the mixture $(200 \mu \mathrm{g} / \mathrm{mL})$ on nitrite level, in isolated mouse cortex specimens. ANOVA, $p<0.001 ;{ }^{* *} p<0.01{ }^{*} p<0.05$ vs. $\mathrm{K}^{+} 60 \mathrm{mM}$. 


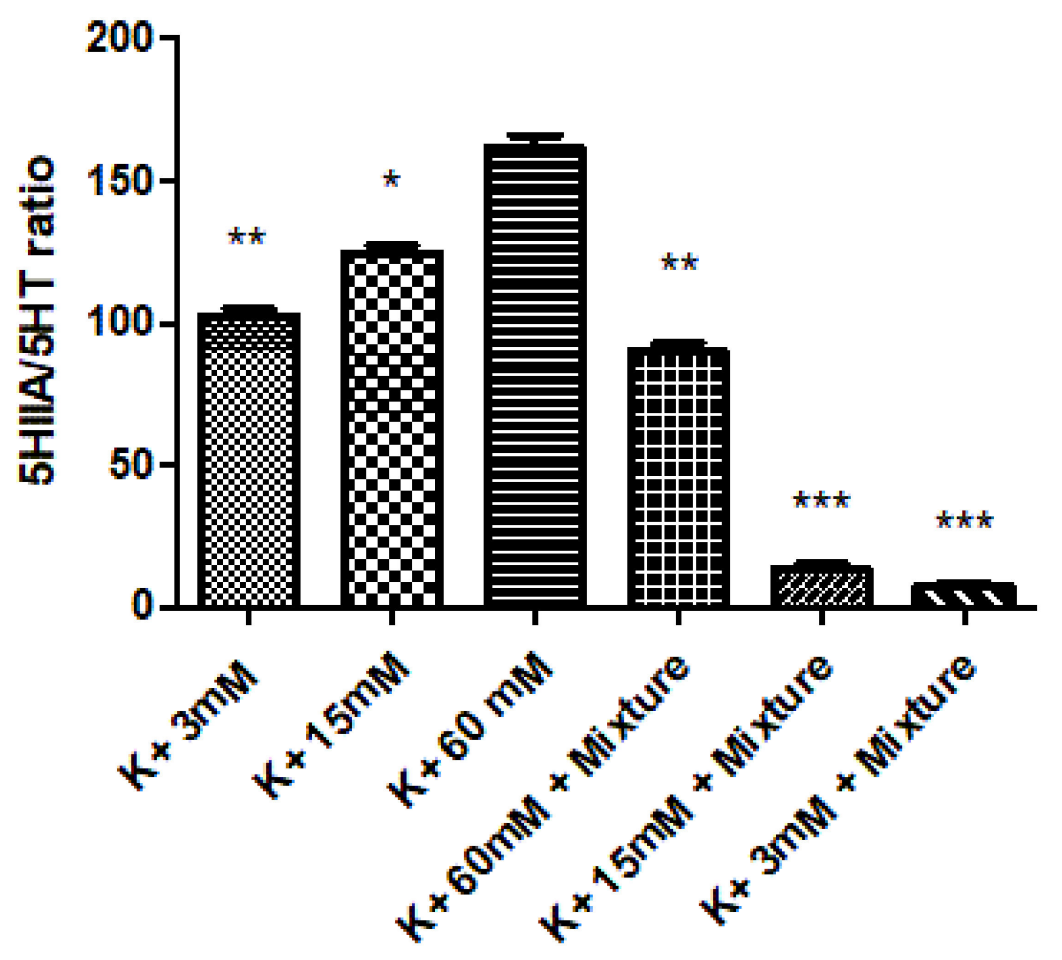

Figure 9. Inhibitory effect induced by the mixture $(200 \mu \mathrm{g} / \mathrm{mL})$ on serotonin degradation (5HIIA/5$\mathrm{HT}$ ), in isolated mouse cortex specimens. ANOVA $p<0.0001,{ }^{* * *} p<0.001,{ }^{* *} p<0.01,{ }^{*} p<0.05$ vs. $\mathrm{K}^{+} 60 \mathrm{mM}$.
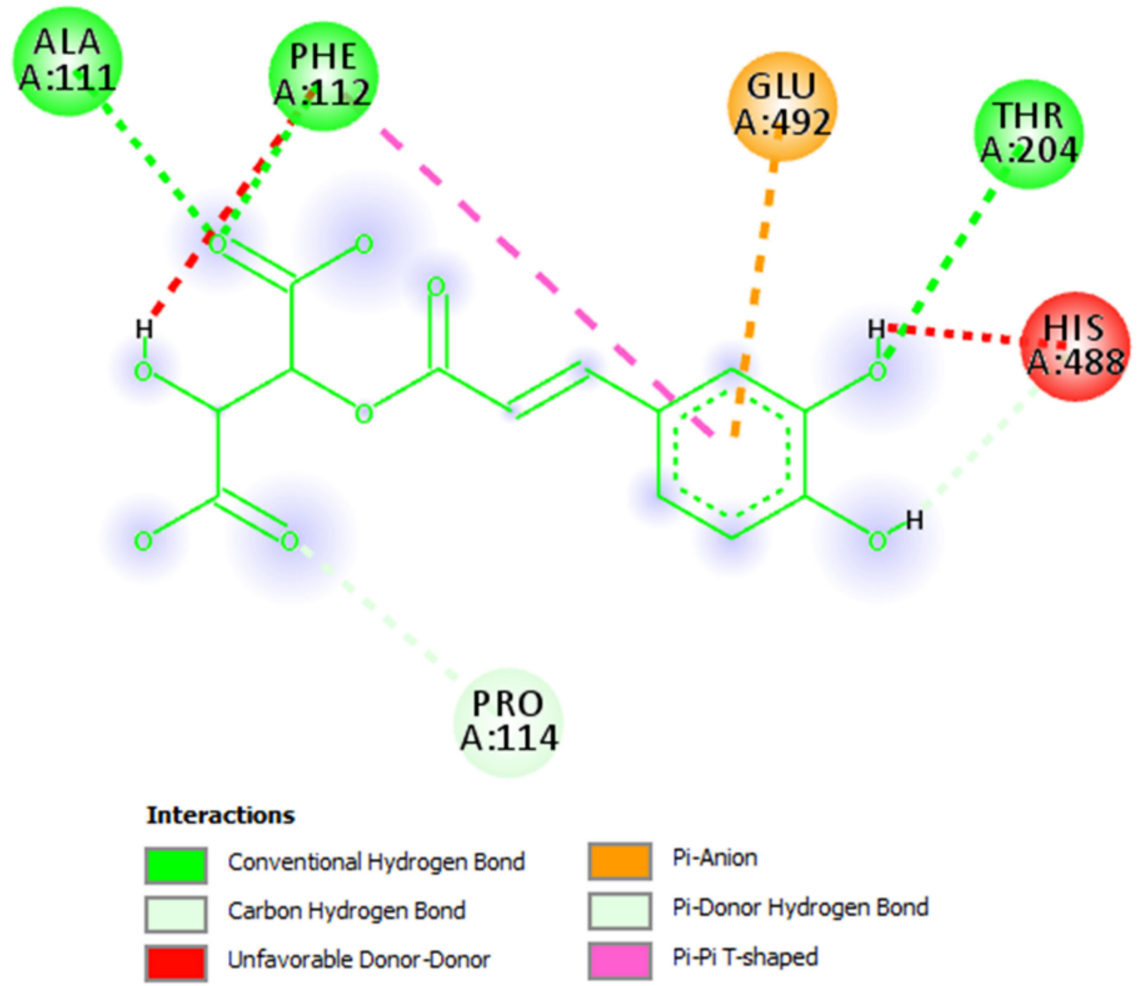

Figure 10. Putative interactions between caftaric acid and monoamine oxydase-A (MAO-A; PDB: 2ZX5). Free energy of binding $(\Delta \mathrm{G})$ and affinity (Ki) are $-7.5 \mathrm{kcal} / \mathrm{mol}$ and $3.2 \mu \mathrm{M}$, respectively. 


\section{Materials and Methods}

\subsection{Extracts}

The dried extracts were provided by Cristalfarma S.r.l. (Milan, Italy). T. parthenium water extract $(0.5 \%$ parthenolide $w / w)$ and $S$. alba extract $(15 \%$ salicin $w / w)$ were rehydrated in water via ultrasound-assisted extraction (Trans-sonic T460 ultrasonic bath; Elma, Singen, Germany), as previously reported [51]. In the mixture, T. parthenium water extract and S. alba extracts were in the ratio $1: 2(w / w)$.

3.2. Qualitative Mass Spectrometer (MS) and High Performance Liquid Chromatography (HPLC) Analysis of Phenolic Compounds

The extract mixture was analyzed qualitatively using an expression compact mass spectrometer (CMS) (Advion, Ithaca, NY, USA) in negative and positive ion mode (m/z scan mode: 100-1200) [52]. Specifically, MS signal identification was realized through comparison with standard solutions and MS spectra present in the recognized Mass Bank Europe database. The mixture was also analyzed for phenol quantitative determination using a reversed-phase HPLC-DAD-MS in gradient elution mode, in agreement with previous studies [18,53]. The details of the analysis are reported in Supplementary Materials (Tables S1 and S2).

\subsection{Protonic Magnetic Resonance $\left({ }^{1} H-N M R\right)$ Analysis}

The extract mixture was analyzed via protonic magnetic resonance $\left({ }^{1} \mathrm{H}-\mathrm{NMR}\right)$. The Variant $300 \mathrm{MHz}$ spectrometer in standard proton pulse sequence (s2pul) with pre-saturation was used for the analysis. $60 \mu \mathrm{L}$ of $\mathrm{D}_{2} \mathrm{O}$ were added as internal lock to $600 \mu \mathrm{L}$ of the sample $(300 \mathrm{mg} / \mathrm{mL})$. Pre-saturation was carried out with relaxation delay $1 \mathrm{~s}$, pulse 45.0 degrees, acquisition time $1.706 \mathrm{~s}$, width $4803.1 \mathrm{~Hz}$ and 128 number of scans; partial water suppression signals occurred around $4.80 \mathrm{ppm}$.

\subsection{Artemia Salina and Daphnia Magna Toxicity Tests}

The biocompatibility and cardiotoxicity of the extract mixture were predicted through the Artemia salina and Daphnia magna toxicity assays. For the A. salina assay, the mixture was tested in the concentration range $0.1-20 \mathrm{mg} / \mathrm{mL}$. Data were expressed as $\mathrm{LC}_{50}$ values. In Daphnia magna, the cardiotoxicity was induced by ethanol $10 \%$ solution. The details about these tests are fully reported in our previous studies $[22,54]$.

\subsection{Ex Vivo CSD Paradigm}

Male adult C57BL6 mice (3-month-old, weight 20-25 g, $\mathrm{N}=24$ ) were sacrificed by $\mathrm{CO}_{2}$ inhalation. The experimentation was approved by Local Ethical Committee (University "G. d'Annunzio" of Chieti-Pescara) and Italian Health Ministry (Italian Health Ministry Authorization Number: F4738.N.5QP). After the sacrifice, cortex specimens were immediately collected and maintained in a thermostatic shaking bath at $37^{\circ} \mathrm{C}$ for $1 \mathrm{~h}$ (incubation period), in Krebs-Ringer buffer at different $\mathrm{K}^{+}$concentrations (3, 15, $\left.60 \mathrm{mM}\right)$.

Specifically, the different $\mathrm{K}^{+}$concentrations corresponded to basal, physiological depolarizing and neurotoxicity stimulus, respectively [55]. During the experimental procedure, isolated cortex was treated with the extract mixture $(200 \mu \mathrm{g} / \mathrm{mL})$.

\subsection{High Performance Liquid Chromatography (HPLC) Analysis of Serotonin and 5-Hydroxyindolacetic Acid}

Cortex serotonin (5-HT) and 5-hydroxyindolacetic acid (5HIIA) were extracted in $\mathrm{HClO}_{4} 50 \mathrm{mM}$ and their levels in the tissue homogenate were analyzed through an HPLCEC apparatus, as previously reported [56]. Details are reported in Supplementary Materials.

\subsection{In Silico Study}

Regarding the docking analysis, the crystal structure of the protein was downloaded from the Protein Data Bank. The PDB code was: 2ZX5 [monoamine oxydase-A: MAO-A]. 
Putative interactions with caftaric acid were analyzed as previously reported [57]. Details are reported in Supplementary Materials.

\subsection{Statistical Analysis}

Statistical analysis was performed by GraphPad Prism ${ }^{\mathrm{TM}}$ (Version 5.00) software (GraphPad Software, Inc., San Diego, CA, USA). The statistical significance $(p<0.05)$ was evaluated through analysis of variance (ANOVA) followed by Newman-Keuls comparison multiple test. Regarding the ex vivo studies, the statistical analysis to calculate the number of animals used in each experiment $(\mathrm{N}=4$ per condition) was performed with the software $G^{*}$ Power (v3.1.9.4). Study potency $(1-\beta)$ and significance level $(\alpha)$ were 0.8 and 0.05 , respectively.

\section{Conclusions}

The results of the present study pointed to the efficacy of the mixture T. parthenium/S. alba, in an experimental model of migraine. In this regard, the mixture showed a good tolerability in cortex tissue, as evidenced by the reduction of LDH and nitrites, biomarkers of cytotoxicity and nitrosative stress, respectively. These effects could be related, albeit partially, to the prominent phytocompounds, namely salicin, caftaric acid and epicatechin. The phytochemical profile is also consistent with the inhibition of serotonin degradation, following cortex treatment, and the efficacy was demonstrated both in basal and neurotoxicity conditions, thus suggesting its use as both protection and prevention agent, in migraine. Based on the phytochemical composition, the inhibition of serotonin degradation could be related to the putative MAO-A inhibition by epicatechin and caftaric acid. Since MAO-A is deeply involved in 5-HT catabolism, and considering the 5-HT depletion occurring in migraine attacks, the inhibition of MAO-A activity could be of relevance in the management/prevention of migraine attacks. Moreover, our results add to a previous perspective study suggesting the association of T. parthenium and S. alba as an innovative pharmacological tool to prevent the onset of migraine, with an acceptable toxicological profile [19]. However, further studies conducted with alternative experimental methods are needed to confirm efficacy, especially through in vivo models, and to improve our knowledge about the mechanism of action.

Supplementary Materials: The following supporting information can be downloaded at: https: / / www.mdpi.com/article/10.3390/pr10020280/s1, Table S1: MS analysis conditions; Table S2: Gradient Elution Conditions.

Author Contributions: Conceptualization, G.O., C.F. and L.M.; methodology, C.F. and M.T.; software, C.F. and L.M.; validation, C.F. and L.M.; formal analysis, C.F. and G.Z.; investigation, A.C., L.R., S.L., A.A., M.L.L., S.C.D.S., C.G., C.C., M.P. and G.Z.; resources, L.M. and C.F.; data curation, C.F. and L.M.; writing-original draft preparation, C.F.; writing-review and editing, S.C.D.S.; A.A.; C.F. and M.T.; visualization, L.B.; supervision, L.M. and G.O.; project administration, L.M., G.O. and C.F.; funding acquisition, L.M., G.O. and C.F. All authors have read and agreed to the published version of the manuscript.

Funding: This work was supported by grants from Cristalfarma S.r.l. (Milan, Italy) that funded the Industrial Ph.D. project of Simonetta Cristina Di Simone entitled: "From the Botanic Garden "Giardino dei Semplici" to modern rational phytotherapy: enhancement of biodiversity and study of plant extracts in complex mixtures for innovative phytotherapic applications". Academic tutors are Luigi Menghini and Claudio Ferrante.

Institutional Review Board Statement: Animal experimental procedures were approved by the local ethical committee (University "G. d'Annunzio" of Chieti-Pescara) and Italian Health Ministry (Italian Health Ministry authorization N. F4738.N.5QP).

Informed Consent Statement: Not applicable.

Data Availability Statement: Not applicable.

Acknowledgments: The present study is part of the third mission activities of the Botanic Garden "Giardino dei Semplici" planned for the 20th anniversary of its establishment. 
Conflicts of Interest: The study was funded by Cristalfarma S.r.l.

Sample Availability: Samples of the compounds are not available from the authors.

\section{References}

1. Rajapakse, T.; Davenport, W.J. Phytomedicines in the treatment of Migraine. CNS Drugs 2019, 33, 399-415. [CrossRef] [PubMed]

2. Hering, R.; Glover, V.; Pattichis, K.; Catarci, T.; Steiner, T.J. 5HT in migraine patients with medication-induced headache. Cephalalgia 1993, 13, 410-412. [CrossRef] [PubMed]

3. Lance, J.W. 5-Hydroxytryptamine and its role in migraine. Eur. Neurol. 1991, 31, 279-281. [CrossRef] [PubMed]

4. Massiou, H.; Bousser, M.G. Prophylactic drug treatment of migraine. Rev. Neurol. 2005, 161, 681-684. [CrossRef]

5. Noseda, R.; Burstein, R. Migraine pathophysiology: Anatomy of the trigeminovascular pathway and associated neurological symptoms, cortical spreading depression, sensitization, and modulation of pain. Pain 2013, 154 (Suppl. S1), S44-S53. [CrossRef] [PubMed]

6. Edvinsson, L.; Haanes, K.A.; Warfvinge, K.; Krause, D.N. CGRP as the target of new migraine therapies-Successful translation from bench to clinic. Nat. Rev. Neurol. 2018, 14, 338-350. [CrossRef] [PubMed]

7. Supornsilpchai, W.; Sanguanrangsirikul, S.; Maneesri, S.; Srikiatkhachorn, A. Serotonin depletion, cortical spreading depression, and trigeminal nociception. Headache 2006, 46, 34-39. [CrossRef] [PubMed]

8. Lupi, C.; Benemei, S.; Guerzoni, S.; Pellesi, L.; Negro, A. Pharmacokinetics and pharmacodynamics of new acute treatments for migraine. Expert Opin. Drug Metab. Toxicol. 2019, 15, 189-198. [CrossRef]

9. Loder, E.; Rizzoli, P. Pharmacologic prevention of migraine: A narrative review of the state of the art in 2018. Headache 2018, 58 (Suppl. S3), 218-229. [CrossRef]

10. Frediani, F.; D'Arrigo, G.; Galli, A.; Altavilla, R.; Di Fiore, P. Exploring new strategy in erenumab therapy for migraine patients. Neurol. Sci. 2020, 41 (Suppl. S2), 507-508. [CrossRef]

11. Wider, B.; Pittler, M.H.; Ernst, E. Feverfew for preventing migraine. Cochrane Database Syst. Rev. 2015, 4, CD002286. [CrossRef]

12. Sangermani, R.; Boncimino, A. The use of nutraceutics in children's and adolescent's headache. Neurol. Sci. 2017, 38 (Suppl. S1), 121-124. [CrossRef]

13. Pareek, A.; Suthar, M.; Rathore, G.S.; Bansal, V. Feverfew (Tanacetum parthenium L.): A systematic review. Pharmacogn. Rev. 2011, 5, 103-110. [CrossRef]

14. Tawfeek, N.; Mahmoud, M.; Hamdan, D.I.; Sobeh, M.; Farrag, N.; Wink, M.; El-Shazly, A.M. Phytochemistry, pharmacology and medicinal uses of plants of the genus salix: An updated review. Front. Pharmacol. 2021, 12, 593856. [CrossRef]

15. Guilbot, A.; Bangratz, M.; Ait Abdellah, S.; Lucas, C. A combination of coenzyme Q10, feverfew and magnesium for migraine prophylaxis: A prospective observational study. BMC Complementary Altern. Med. 2017, 17, 433. [CrossRef]

16. Moscano, F.; Guiducci, M.; Maltoni, L.; Striano, P.; Ledda, M.G.; Zoroddu, F.; Raucci, U.; Villa, M.P.; Parisi, P. An observational study of fixed-dose Tanacetum parthenium nutraceutical preparation for prophylaxis of pediatric headache. Ital. J. Pediatr. 2019, 45, 36. [CrossRef]

17. Ulrich-Merzenich, G.; Kelber, O.; Koptina, A.; Freischmidt, A.; Heilmann, J.; Müller, J.; Zeitler, H.; Seidel, M.F.; Ludwig, M.; Heinrich, E.; et al. Novel neurological and immunological targets for salicylate-based phytopharmaceuticals and for the anti-depressant imipramine. Phytomedicine 2012, 19, 930-939. [CrossRef]

18. Di Giacomo, V.; Ferrante, C.; Ronci, M.; Cataldi, A.; Di Valerio, V.; Rapino, M.; Recinella, L.; Chiavaroli, A.; Leone, S.; VladimirKnežević, S.; et al. Multiple pharmacological and toxicological investigations on Tanacetum parthenium and Salix alba extracts: Focus on potential application as anti-migraine agents. Food Chem. Toxicol. 2019, 133, 110783. [CrossRef]

19. Recinella, L.; Chiavaroli, A.; di Giacomo, V.; Antolini, M.D.; Acquaviva, A.; Leone, S.; Brunetti, L.; Menghini, L.; Ak, G.; Zengin, G.; et al. Anti-Inflammatory and neuromodulatory effects induced by tanacetum parthenium water extract: Results from in silico, in vitro and ex vivo studies. Molecules 2021, 26, 22. [CrossRef]

20. Shrivastava, R.; Pechadre, J.C.; John, G.W. Tanacetum parthenium and Salix alba (Mig-RL) combination in migraine prophylaxis: A prospective, open-label study. Clin. Drug Investig. 2006, 26, 287-296. [CrossRef]

21. Orlando, G.; Zengin, G.; Ferrante, C.; Ronci, M.; Recinella, L.; Senkardes, I.; Gevrenova, R.; Zheleva-Dimitrova, D.; Chiavaroli, A.; Leone, S.; et al. Comprehensive chemical profiling and multidirectional biological investigation of two wild anthemis species (Anthemis Tinctoria var. pallida and A. Cretica subsp. Tenuiloba): Focus on neuroprotective effects. Molecules 2019, $24,2582$. [CrossRef] [PubMed]

22. Chiavaroli, A.; Balaha, M.; Acquaviva, A.; Ferrante, C.; Cataldi, A.; Menghini, L.; Rapino, M.; Orlando, G.; Brunetti, L.; Leone, S.; et al. Phenolic characterization and neuroprotective properties of grape pomace extracts. Molecules 2021, $26,6216$. [CrossRef] [PubMed]

23. Zhao, A.Q.; Zhao, J.H.; Zhang, S.Q.; Pan, Y.Y.; Huo, X.L. Determination of parthenolide in rat plasma by UPLC-MS/MS and its application to a pharmacokinetic study. J. Pharm. Biomed. Anal. 2016, 119, 99-103. [CrossRef] [PubMed]

24. Kammerer, B.; Kahlich, R.; Biegert, C.; Gleiter, C.H.; Heide, L. HPLC-MS/MS analysis of willow bark extracts contained in pharmaceutical preparations. Phytochem. Anal. 2005, 16, 470-478. [CrossRef] [PubMed] 
25. Maier, T.; Sanzenbacher, S.; Kammerer, D.R.; Berardini, N.; Conrad, J.; Beifuss, U.; Carle, R.; Schieber, A. Isolation of hydroxycinnamoyltartaric acids from grape pomace by high-speed counter-current chromatography. J. Chromatogr. A 2006, 1128, 61-67. [CrossRef] [PubMed]

26. Mavrommatis, A.; Giamouri, E.; Myrtsi, E.D.; Evergetis, E.; Filippi, K.; Papapostolou, H.; Koulocheri, S.D.; Zoidis, E.; Pappas, A.C.; Koutinas, A.; et al. Antioxidant Status of Broiler Chickens Fed Diets Supplemented with Vinification By-Products: A Valorization Approach. Antioxidants 2021, 10, 1250. [CrossRef]

27. Gómez-Mejía, E.; Mikkelsen, L.H.; Rosales-Conrado, N.; León-González, M.E.; Madrid, Y.A. Combined approach based on matrix solid-phase dispersion extraction assisted by titanium dioxide nanoparticles and liquid chromatography to determine polyphenols from grape residues. J. Cromatogr. A 2021, 1644, 462128. [CrossRef]

28. Goufo, P.; Singh, R.K.; Cortez, I. A reference list of phenolic compounds (including stilbenes) in Grapevine (Vitis vinifera L.) roots, woods, canes, stems, and leaves. Antioxidants 2020, 9, 398. [CrossRef]

29. Emre, İ. The biochemical content and antioxidant capacities of endemic Tanacetum densum (Lab.) Schultz Bip. subsp. laxum, and Tanacetum densum (Lab.) Schultz Bip. subsp. amani Heywood growing in Turkey. Braz. J. Biol. 2021, 81, 1106-1114. [CrossRef]

30. Muresan, M.; Benedec, D.; Vlase, L.; Oprean, R.; Toiu, A.; Oniga, I. Screening of polyphenolic compounds, antioxidant and antimicrobial properties of Tanacetum vulgare from Transylvania. Studia UBB Chem. 2015, 1, 127-138.

31. Wu, C.; Chen, F.; Wang, X.; Wu, Y.; Dong, M.; He, G.; Galyean, R.D.; He, L.; Huang, G. Identification of antioxidant phenolic compounds in feverfew (Tanacetum parthenium) by HPLC-ESI-MS/MS and NMR. Phytochem. Anal. 2007, 18, 401-410. [CrossRef]

32. Budny, M.; Zalewski, K.; Stolarski, M.J.; Wiczkowski, W.; Okorski, A.; Stryiński, R. The phenolic compounds in the young shoots of selected willow cultivars as a determinant of the plants' attractiveness to cervids (Cervidae, Mammalia). Biology 2021, 10, 612 [CrossRef]

33. Politi, M.; Zloh, M.; Pintado, M.E.; Castro, P.M.; Heinrich, M.; Prieto, J.M. Direct metabolic fingerprinting of commercial herbal tinctures by nuclear magnetic resonance spectroscopy and mass spectrometry. Phytochem. Anal. 2009, 20, 328-334. [CrossRef]

34. Anastasiadi, M.; Zira, A.; Magiatis, P.; Haroutounian, S.A.; Skaltsounis, A.L.; Mikros, E. 1H NMR-based metabonomics for the classification of Greek wines according to variety, region, and vintage. Comparison with HPLC data. J. Agric. Food Chem. 2009, 57, 11067-11074. [CrossRef]

35. Boffo, E.F.; Tavares, L.A.; Tobias, A.C.; Ferreira, M.M.; Ferreira, A.G. Identification of components of Brazilian honey by 1H NMR and classification of its botanical origin by chemometric methods. LWT 2012, 49, 55-63. [CrossRef]

36. Orlando, G.; Recinella, L.; Chiavaroli, A.; Brunetti, L.; Leone, S.; Carradori, S.; Di Simone, S.; Ciferri, M.C.; Zengin, G.; Ak, G.; et al. Water extract from inflorescences of industrial hemp futura 75 variety as a source of anti-inflammatory, anti-proliferative and antimycotic agents: Results from in silico, in vitro and ex vivo studies. Antioxidants 2020, 9, 437. [CrossRef]

37. Wang, Z.; Hwang, S.H.; Lim, S.S. Comprehensive profiling of minor tyrosinase inhibitors from Gastrodia elata using an off-line hyphenation of ultrafiltration, high-speed countercurrent chromatography, and high-performance liquid chromatography. J. Chromatogr. A 2017, 1529, 63-71. [CrossRef]

38. Hwang, S.H.; Kim, H.-Y.; Guillen Quispe, Y.N.; Wang, Z.; Zuo, G.; Lim, S.S. Aldose reductase, protein glycation inhibitory and antioxidant of peruvian medicinal plants: The case of Tanacetum parthenium L. and its constituents. Molecules 2019, 24, 2010. [CrossRef]

39. Ostolski, M.; Adamczak, M.; Brzozowski, B.; Wiczkowski, W. Antioxidant activity and chemical characteristics of supercritical $\mathrm{CO}_{2}$ and water extracts from willow and poplar. Molecules 2021, 26, 545. [CrossRef]

40. Ramos, P.A.B.; Moreirinha, C.; Silva, S.; Costa, E.M.; Veiga, M.; Coscueta, E.; Santos, S.A.O.; Almeida, A.; Pintado, M.M.; Freire, C.S.R.; et al. The health-promoting potential of Salix spp. Bark polar extracts: Key insights on phenolic composition and in vitro bioactivity and biocompatibility. Antioxidants 2019, 8, 609. [CrossRef]

41. Faria, A.; Pestana, D.; Teixeira, D.; Couraud, P.O.; Romero, I.; Weksler, B.; de Freitas, V.; Mateus, N.; Calhau, C. Insights into the putative catechin and epicatechin transport across blood-brain barrier. Food Funct. 2011, 2, 39-44. [CrossRef]

42. Radulović, N.S.; Genčić, M.S.; Stojanović, N.M.; Randjelović, P.J.; Stojanović-Radić, Z.Z.; Stojiljković, N.I. Toxic essential oils. Part V: Behaviour modulating and toxic properties of thujones and thujone-containing essential oils of Salvia officinalis L.; Artemisia absinthium L.; Thuja occidentalis L. and Tanacetum vulgare L. Food Chem. Toxicol. 2017, 105, 355-369. [CrossRef] [PubMed]

43. Cobley, J.N.; Fiorello, M.L.; Bailey, D.M. 13 reasons why the brain is susceptible to oxidative stress. Redox. Biol. 2018, 15, 490-503. [CrossRef]

44. Halliwell, B.; Clement, M.V.; Ramalingam, J.; Long, L.H. Hydrogen peroxide. Ubiquitous in cell culture and in vivo? IUBMB Life 2000, 50, 251-257. [CrossRef] [PubMed]

45. Cannizzaro, C.; D'Amico, M.; Preziosi, P.; Martire, M. Presynaptic effects of anandamide and WIN55, 212-2 on glutamatergic nerve endings isolated from rat hippocampus. Neurochem. Int. 2006, 48, 159-165. [CrossRef] [PubMed]

46. Larner, S.F.; Wang, J.; Goodman, J.; Altman, M.B.O.; Xin, M.; Wang, K.K.W. In vitro neurotoxicity resulting from exposure of cultured neural cells to several types of nanoparticles. J. Cell Death 2017, 10. [CrossRef] [PubMed]

47. Tsikas, D. Assessment of lipid peroxidation by measuring malondialdehyde (MDA) and relatives in biological samples: Analytical and biological challenges. Anal. Biochem. 2017, 524, 13-30. [CrossRef] [PubMed]

48. Lee, J.J.; Chang, C.K.; Liu, I.M.; Chi, T.C.; Yu, H.J.; Cheng, J.T. Changes in endogenous monoamines in aged rats. Clin. Exp. Pharmacol. Physiol. 2001, 28, 285-289. [CrossRef] 
49. Chatatikun, M.; Supjaroen, P.; Promlat, P.; Chantarangkul, C.; Waranuntakul, S.; Nawarat, J.; Tangpong, J.; Chiabchalard, A. Antioxidant and tyrosinase inhibitor properties of an aqueous extract og Garcinia atrovirdis Griff. Ex. T. Anderson fruit pericarps. Pharmacogn. J. 2020, 12, 71-78. [CrossRef]

50. Reinheimer, J.B.; Bressan, G.N.; de Freitas, C.M.; Ceretta, A.P.C.; Krum, B.N.; Nogara, P.A.; Rodrigues, T.; Schwerz, J.P.; da Rocha, J.B.T.; Fachinetto, R. Effects of CATECHIN on reserpine-induced vacuous chewing movements: Behavioral and biochemical analysis. Naunyn-Schmiedeberg. Arch. Pharmacol. 2020, 393, 2439-2452. [CrossRef]

51. Wang, Z.; Hwang, S.H.; Lim, S.S. Characterization of DHDP, a novel aldose reductase inhibitor isolated from Lysimachia christinae. J. Funct. Foods 2017, 37, 241-248. [CrossRef]

52. Menghini, L.; Leporini, L.; Vecchiotti, G.; Locatelli, M.; Carradori, S.; Ferrante, C.; Zengin, G.; Recinella, L.; Chiavaroli, A.; Leone, S.; et al. Crocus sativus L. stigmas and byproducts: Qualitative fingerprint, antioxidant potentials and enzyme inhibitory activities. Food Res. Int. 2018, 109, 91-98. [CrossRef]

53. Ferrante, C.; Chiavaroli, A.; Angelini, P.; Venanzoni, R.; Angeles Flores, G.; Brunetti, L.; Petrucci, M.; Politi, M.; Menghini, L.; Leone, S.; et al. Phenolic content and antimicrobial and anti-inflammatory effects of solidago virga-aurea, phyllanthus niruri, epilobium angustifolium, peumus boldus, and ononis spinosa extracts. Antibiotics 2020, 9, 783. [CrossRef]

54. Orlando, G.; Chiavaroli, A.; Adorisio, S.; Delfino, D.V.; Brunetti, L.; Recinella, L.; Leone, S.; Zengin, G.; Acquaviva, A.; Angelini, P.; et al. Unravelling the phytochemical composition and the pharmacological properties of an optimized extract from the fruit from Prunus mahaleb L.: From traditional liqueur market to the pharmacy shelf. Molecules 2021, 26, 4422. [CrossRef]

55. Raiteri, L.; Stigliani, S.; Zedda, L.; Raiteri, M.; Bonanno, G. Multiple mechanisms of transmitter release evoked by "pathologically" elevated extracellular $\left[\mathrm{K}^{+}\right]$: Involvement of transporter reversal and mitochondrial calcium. J. Neurochem. 2002, 80, 706-714. [CrossRef]

56. Orlando, G.; Leone, S.; Ferrante, C.; Chiavaroli, A.; Mollica, A.; Stefanucci, A.; Macedonio, G.; Dimmito, M.P.; Leporini, L.; Menghini, L.; et al. Effects of Kisspeptin-10 on Hypothalamic Neuropeptides and Neurotransmitters Involved in Appetite Control. Molecules 2018, 23, 3071. [CrossRef]

57. Vasileva, L.V.; Savova, M.S.; Amirova, K.M.; Balcheva-Sivenova, Z.; Ferrante, C.; Orlando, G.; Wabitsch, M.; Georgiev, M.I. Caffeic and chlorogenic acids synergistically activate browning program in human adipocytes: Implications of AMPK- and PPAR-mediated pathways. Int. J. Mol. Sci. 2020, 21, 9740. [CrossRef] 